\title{
A VALORIZAÇÃO DA IDENTIDADE CULTURAL COMO DESAFIO À CONCRETIZAÇÃO DO DIREITO AO DESENVOLVIMENTO
}

\section{THE ENHANCEMENT OF CULTURAL IDENTITY AS A CHALLENGE TO CONCRETIZATION OF THE RIGHT TO DEVELOPMENT}

\author{
Lívia Gaigher Campello
}

\begin{abstract}
Pós-Doutorado em Direito do Estado pela Universidade de São Paulo - USP, Doutorado em Direito das Relações Econômicas e Internacionais pela Pontifícia Universidade Católica de São Paulo - PUC/SP e Mestrado em Políticas Públicas e Processo pelo Centro Universitário Fluminense - UNIFLU. Professora adjunta da Faculdade de Direito na Universidade Federal de Mato Grosso do Sul (UFMS). Coordenadora do Programa de Mestrado em Direitos Humanos da UFMS. Coordenadora do Projeto de Pesquisa "Cooperação Internacional e Meio Ambiente" (MS/FUNDECT). Líder do Grupo de Pesquisa "Direitos Humanos, Meio Ambiente e Desenvolvimento Sustentável Global" (CNPq). Editora-chefe da Revista Direito UFMS. E-mail: livia.campello@ufms.br
\end{abstract}

\section{Mariana Ribeiro Santiago}

Doutora em Direito Civil Comparado pela Pontifícia Universidade Católica de São Paulo (2012), sob a orientação da Profa. Dra. Maria Helena Diniz. Mestra em Direito civil comparado pela Pontifícia Universidade Católica de São Paulo (2004), sob a orientação da

Profa. Dra. Maria Helena Diniz. Especialista em direito contratual pela Pontifícia

Universidade Católica de São Paulo (2002). Graduada em Direito pela Universidade

Federal da Bahia (1999). Professora do Programa de Mestrado e Doutorado em Direito e

da Graduação em Direito da Universidade de Marília - UNIMAR. Professora da

Graduação em Direito da Universidade Nove de Julho - UNINOVE. Editora-chefe da Revista Argumentum (Qualis B1). E-mail: mariana@nbsadvogados.com.br

\section{Sinara Lacerda Andrade}

\begin{abstract}
Doutoranda e Mestre em Direito pela Universidade de Marília/SP (UNIMAR). Especialista em Direito Processual Penal com ênfase em Docência do Ensino Superior pela Universidade Gama Filho, Rio de Janeiro/RJ (UGF). Bacharel em Direito pela Universidade do Estado de Minas Gerais (UEMG). Professora Assistente do Programa de Mestrado em Direito da Universidade de Marília/SP (UNIMAR). Avaliadora Associada ao Conselho Nacional de Pesquisa e Pós-graduação em Direito (CONPEDI). Assessora, consultora e advogada. E-mail: sinaralacerda.adv@hotmail.com
\end{abstract}

Recebido em: 11/08/2017

Aprovado em: 15/12/2017

RESUMO: O presente artigo analisa o desenvolvimento enquanto direito humano de solidariedade, em sua conexão com o aspecto cultural. De início, a pesquisa aborda a relação entre o processo de globalização e a necessidade de preservação da identidade cultural nacional. Na sequência, trata do impacto da desapropriação cultural no desenvolvimento. A escolha do tema se justifica diante da necessidade de promoção do desenvolvimento em uma sociedade 
marcada por paradoxos, desigualdades e caos em vários aspectos sociais. Observa-se que a desapropriação cultural causa profundos prejuízos para os países em desenvolvimento, contribuindo para a inefetividade do direito ao desenvolvimento. O que se pretende, como objetivo, é apresentar um novo caminho para a efetividade do direito ao desenvolvimento, a partir de iniciativas de solidariedade voltadas à garantia da manutenção da cultura. Na abordagem, utilizou-se os método dedutivo, envolvendo, ainda, pesquisa descritiva, explicativa, bibliográfica e documental.

Palavras-chave: Globalização; Identidade Cultural; Solidariedade; Desenvolvimento.

ABSTRACT: The present paper analyzes the development as a human right of solidarity, in its connection with the cultural aspect. At first, the research addresses the relationship between the process of globalization and the need to preserve national cultural identity. Next, it deals with the impact of cultural expropriation on development. The choice of theme is justified by the need to promote development in a society marked by paradoxes, inequalities and chaos in various social aspects. What is intended, as an objective, is to present a concrete response to the effectiveness of the right to development, based on initiatives of solidarity. In conclusion, it is noted that cultural expropriation causes profound damage to developing countries, contributing to the ineffectiveness of the right to development. In the approach, the deductive method was used, also involving descriptive, explanatory, bibliographical and documentary research.

Keywords: Globalization; Cultural Identity; Solidarity; Development.

SUMÁRIO: Introdução. 1. Notas sobre cultura no mundo globalizado. 2. O impacto da desapropriação cultural no direito ao desenvolvimento. 3. O papel das Organizações NãoGovernamentais na luta pela manutenção da cultura nacional. 4. O caminho da solidariedade. Conclusão. Referências Bibliográficas.

\section{INTRODUÇÃO}

A proposta do presente trabalho é analisar o desenvolvimento enquanto direito humano de solidariedade, abordando o aspecto cultural como elemento fundamental para a sua efetividade, bem como os prejuízos da desapropriação cultural para os países em desenvolvimento.

Para tanto, abordar-se-á no primeiro tópico a relação entre o processo de globalização, o seu impacto no âmbito da cultura, e a necessidade de preservação da identidade cultural dos povos.

O segundo tópico será dedicado à análise do impacto da desapropriação cultural no desenvolvimento, que se observa quando da introdução, nos países em desenvolvimento, dos valores do mundo ocidental, em desrespeito à cultura local.

Na sequência, será dado enfoque às Organizações Não-Governamentais, sua capacidade de atuação e alcance junto aos países em desenvolvimento, bem como o seu papel na luta pela manutenção da cultura nacional.

No último tópico, será analisado o princípio da solidariedade e sua relação com o desenvolvimento nacional, através do respeito à diversidade cultural, garantindo, por tal via, o sentimento coalizão existente entre os povos.

Objetiva-se com o presente estudo apresentar um caminho no que concerne à inefetividade do Direito ao tentar positivar questões humanísticas de cunho subjetivo, demonstrando que somente por meio da solidariedade e cooperação será possível promover uma mudança de paradigma e o desenvolvimento humano, notadamente no campo que envolve a preservação cultural. 
O estudo justifica-se pela complexidade da sociedade e pelo caos instaurado em vários aspectos sociais, devido à falta de ações que fomentem e promovam a solidariedade como fundamento para as relações sociais e preservação da identidade cultural, sejam elas de cunho público ou privado.

Por fim, acerca do tipo e metodologia da pesquisa, quanto aos fins far-se-á uma investigação descritiva e explicativa e quanto aos meios utilizar-se-á a pesquisa bibliográfica e documental, com amparo na doutrina estrangeira e nacional, bem como análise de índices e estatísticas. Na abordagem, será utilizado o método dedutivo, partindo-se da análise de observações gerais para alcançar as especificidades da temática proposta.

\section{NOTAS SOBRE CULTURA NO MUNDO GLOBALIZADO}

A globalização traz transformações e gera efeitos em praticamente todos os aspectos da vida, positivas e negativas, muito além dos aspectos econômicos. Também pode ser caracterizada como um fenômeno político, tecnológico e cultural, tendo sido fortemente influenciada pelo incremento dos sistemas de comunicação observados no final da década de $1960^{1}$.

De acordo com Edgar Morin, há uma relação entre a globalização de hoje com o processo de conquista das Américas e a expansão do ocidente europeu sobre o planeta. Conforme o referido autor, a primeira unificação mundial danosa para todos é a globalização dos micróbios, como a tuberculose e outras enfermidades europeias que chegaram às Américas ao longo dos anos, e os micróbios americanos, como os da sífilis, que também chegaram à Europa. O dano principal, contudo, inegavelmente coube aos conquistados, se considerarmos o processo de escravização de suas populações, dos negros que foram transportados para as Américas e dos povos colonizados ${ }^{2}$.

Tal quadro de dominação começa a mudar entre o final do Século XIX e o Século XX, quando se inicia o processo de descolonização ou a emancipação relativa dos povos conquistados e escravizados. Após a derrubada do Muro de Berlim e o fim do império soviético, fica evidente a hegemonia norte-americana no mercado mundial, com a dominação tecnológica e econômica do Ocidente ${ }^{3}$.

A globalização, nas suas vestes atuais, inicia-se em 1989, após a queda das economias ditas socialistas, tendo como causa a expansão do capitalismo por todos os continentes, somado ao surgimento das redes de telecomunicações instantâneas. Como resultado, verificou-se a unificação tecnoeconômica do planeta, bem como uma onda democratizante em diversas nações, acompanhada da valorização dos direitos do homem e dos direitos da mulher, cujos resultados ainda permanecem incertos ${ }^{4}$.

Nota-se, em decorrência dessa conjuntura, a existência de uma textura de sociedademundo, com um território que comporta intercomunicações permanentes e uma economia mundializada. Todavia, levando-se em conta que uma sociedade deve controlar sua economia, este aspecto atualmente exibe falhas. Faltam, ainda, autoridades legítimas, dotadas de poderes de decisão, e a consciência de uma comunidade transnacional ${ }^{5}$.

\footnotetext{
${ }^{1}$ GIDDENS, Anthony. Mundo em descontrole. Trad. Maria Luiza X. de A. Borges. 2 ed.. Rio de Janeiro: Record, 2002. pp. 17, 20-21.

${ }^{2}$ MORIN, Edgar. As duas globalizações: complexidade e comunicação, uma pedagogia do presente. Porto alegre: Sulina - Edipucrs, 2001. p. 39.

${ }^{3}$ MORIN, Edgar. As duas globalizações: complexidade e comunicação, uma pedagogia do presente. Porto alegre: Sulina - Edipucrs, 2001. p. 40.

${ }^{4}$ MORIN, Edgar. A via para o futuro da humanidade. Tradução Edgard de Assis Carvalho e Mariza Perassi Bosco. Rio de Janeiro: Bertrand Brasil, 2013. p. 21.

${ }^{5}$ MORIN, Edgar. A via para o futuro da humanidade. Tradução Edgard de Assis Carvalho e Mariza Perassi Bosco. Rio de Janeiro: Bertrand Brasil, 2013. pp. 21-22.
} 
Sobre a crise decorrente da unificação tecnoeconômica do globo, Edgar Morin ${ }^{6}$ entende que:

Existe uma coincidência entre a proliferação de Estados soberanos, o crescimento de sua interdependência e de seu fechamento etnorreligioso. Essa coincidência não é fortuita. Ela se explica: a) pelas resistências nacionais, étnicas e culturais à ocidentalização; b) pela queda generalizada da esperança depositada no Progresso. (...) Concomitantemente, e a despeito da hegemonia tecnoeconômica e militar dos Estados Unidos, desenvolve-se um mundo multipolar dominado por blocos de interesses simultaneamente cooperativos e conflitantes, em que as múltiplas crises aumentam as necessidades de cooperação e, ao mesmo tempo, os riscos de conflitos. (...) Dessa forma, a globalização, simultaneamente una e plural, conhece sua própria crise, que reúne e desune, unifica e separa.

Com efeito, parece haver um mal-estar em torno da noção de globalização, tendo em vista o seu caráter indeterminado, indisciplinado e de autopropulsão dos assuntos mundiais. Não há claramente um centro, uma comissão diretora, alguém que está no controle. Não se pode precisar nem mesmo o que seria estar no controle. A globalização não se refere apenas às iniciativas e aos empreendimentos globais desejados, mas também aos efeitos mundiais não pretendidos e imprevistos ${ }^{7}$.

Por outro lado, dita conjuntura repercute diretamente na questão do poder e da soberania dos Estados. Segundo Bauman ${ }^{8}$, "num mundo em que o capital não tem domicílio fixo e os fluxos financeiros estão bem além do controle dos governos nacionais, muitas das alavancas da política econômica não mais funcionam". O Estado permanece, assim, com as suas necessidades básicas, seu poder de repressão, quiçá um serviço de segurança para as megaempresas ${ }^{9}$.

Há autores que defendem que a globalização envolve concomitantemente três grandes processos, desenvolvendo-se de maneira integrada: a mundialização, relacionada com os fenômenos do consumismo, da massificação e da homogeneização de estilos de vida, atrelada à dimensão cultural; a planetarização, associada às políticas governamentais e às instituições, responsável pela "miniaturarização" do Estado-nação; e a globalização tecnológica, afetando diretamente os modos de produzir, impulsionados por redes transnacionais, de produção, finanças e comércio ${ }^{10}$.

Muito se especula, atualmente, se a globalização está se desenvolvendo de uma forma equânime ou se gera um processo de "ocidentalização", por exemplo, por intermédio da internacionalização maciça de marcas como Coca-Cola e McDonald's, acirrando as diferenças sociais, num novo processo de imperialização ou "pilhagem global"" .

Em termos análogos, há o entendimento de que o processo de globalização é desigual e não contínuo, e nem tampouco se mostra como distribuidor de riquezas, mas, ao contrário,

\footnotetext{
${ }^{6}$ MORIN, Edgar. A via para o futuro da humanidade. Tradução Edgard de Assis Carvalho e Mariza Perassi Bosco. Rio de Janeiro: Bertrand Brasil, 2013. pp. 23-24.

${ }^{7}$ BAUMAN, Zygmunt. Globalização: as consequências humanas. Tradução Marcus Penchel. Rio de Janeiro: Zahar, 1999. pp. 66-68.

${ }^{8}$ BAUMAN, Zygmunt. Globalização: as consequências humanas. Tradução Marcus Penchel. Rio de Janeiro: Zahar, 1999. p. 64.

${ }^{9}$ BAUMAN, Zygmunt. Globalização: as consequências humanas. Tradução Marcus Penchel. Rio de Janeiro: Zahar, 1999. p. 74.

${ }^{10}$ DELGADO, Ana Paula Teixeira. $O$ direito ao desenvolvimento na perspectiva da globalização: paradoxos $e$ desafios. Rio de Janeiro: Renovar, 2001. pp. 5-6. DREIFUSS, René Armand. A época das perplexidades: mundialização, globalização e planetarização: novos desafios. Petrópolis: Vozes, 1997. p. 133.

${ }^{11}$ GIDDENS, Anthony. Mundo em descontrole. Trad. Maria Luiza X. de A. Borges. 2 ed.. Rio de Janeiro: Record, 2002. pp. 25-26.
} 
concentra e acresce recursos nas mãos de poucos, principalmente das grandes potências mundiais, ou seja, os grandes capitalistas, o que pode conduzir à conclusão de que o desenvolvimento econômico é um mito, algo inalcançável para os países periféricos ${ }^{12}$.

Milton Santos ${ }^{13}$, referência nacional sobre o tema, ao caracterizar a globalização como uma fábula e destacar o seu uso ideológico e político, afirma:

Fala-se, por exemplo, em aldeia global para fazer crer que a difusão instantânea de notícias realmente informa as pessoas. A partir desse mito e do encurtamento das distâncias - para aqueles que realmente podem viajar - também se difunde a noção de tempo e espaço contraídos. É como se o mundo se houvesse tornado, para todos, ao alcance da mão. Um mercado avassalador dito global é apresentado como capaz de homogeneizar o planeta quando, na verdade, as diferenças locais são aprofundadas. Há uma busca de uniformidade, ao serviço dos atores hegemônicos, mas o mundo se torna menos unido, tornando mais distante o sonho de uma cidadania verdadeiramente universal. Enquanto isso, o culto ao consumo é estimulado.

Nessa linha, Joseph Stiglitz ${ }^{14}$ afirma que a globalização, como tem sido conduzida, para muitos assemelha-se mais a um desastre iminente, pelo seu impacto sobre o modo de vida e os valores básicos da sociedade nos países em desenvolvimento.

Conforme o referido autor ${ }^{15}$,

Se a globalização não logrou êxito em reduzir a pobreza, também não teve sucesso em garantir estabilidade. As crises na Ásia e na América Latina têm ameaçado as economias e a estabilidade de todos os países em desenvolvimento. Existe o medo de o contágio financeiro se espalhar por todo o mundo, de que a queda da moeda de um mercado emergente signifique que outras também vão cair. Por algum tempo, em 1997 e 1998, a crise asiática parecia representar uma ameaça para toda a economia mundial.

É inegável que muitos dos aspectos da globalização foram bem-vindos em todos os lugares, como o aumento da expectativa de vida e do padrão de vida no mundo, a redução do isolamento das nações em desenvolvimento, a ampliação do acesso ao conhecimento e à novas tecnologias etc. ${ }^{16}$.

Os aspectos econômicos, por sua vez, são os que têm gerado mais controvérsia, inclusive no que tange à atuação das três principais instituições envolvidas nesse contexto: o Fundo Monetário Internacional - FMI, o Banco Mundial e a Organização Mundial do Comércio $\mathrm{OMC}^{17}$.

A conclusão de que a globalização, a par dos seus inegáveis benefícios para a humanidade, acima mencionados, também avança de forma daninha, ampliando o foco da desigualdade social e devastando culturas locais, numa nova roupagem de imperialismo, sinaliza

\footnotetext{
${ }^{12}$ FURTADO, Celso. O mito do desenvolvimento econômico. 4 ed. Rio de Janeiro: Paz e Terra, 1974. pp. 75-76.

${ }^{13}$ SANTOS, Milton. Por uma outra globalização: do pensamento único à consciência universal. 6 ed.. Rio de Janeiro: Record, 2001. pp. 18-19.

${ }^{14}$ STIGLITZ, Joseph E. A Globalização e seus malefícios: a promessa não cumprida de benefícios globais. São Paulo: Futura, 2002. p. 48.

${ }^{15}$ STIGLITZ, Joseph E. A Globalização e seus malefícios: a promessa não cumprida de benefícios globais. São Paulo: Futura, 2002. p. 32.

${ }^{16}$ STIGLITZ, Joseph E. A Globalização e seus malefícios: a promessa não cumprida de benefícios globais. São Paulo: Futura, 2002. pp. 30-31.

${ }^{17}$ STIGLITZ, Joseph E. A Globalização e seus malefícios: a promessa não cumprida de benefícios globais. São Paulo: Futura, 2002. pp. 36-37.
}

Revista de Direito Brasileira | São Paulo, SP | v. 19 | n. 8 | p. 3- 19 |Jan./Abr. 2018 
a necessidade do fortalecimento e da valorização da identidade cultural nacional, como um fator de resistência a este processo.

Cultura é uma palavra abrangente que pode absorver muitos significados. A própria palavra cultura foi incorporada a nossa linguagem com seu significado atual em tempos recentes. Há não mais do que 300 (trezentos) anos o significado de cultura deixou de se vincular à ideia de cultivar a terra, para assumir um teor mais abstrato, cultivar o espírito ${ }^{18}$. $\mathrm{Na}$ atualidade, vários termos podem se associar à cultura, como cultura de massa, patrimônio cultural, cultura popular, identidade cultural e diversidade cultural.

Segundo Thierry G. Verhelst ${ }^{19}$, "a cultura é o conjunto de soluções originais que um grupo de seres humanos inventa, a fim de se adaptar ao seu ambiente natural e social". Trata-se, assim, de algo que abrange todos os aspectos da vida, como conhecimentos técnicos, costumes em geral, religião, valores, língua, comportamento socioeconômico etc.

A Constituição da República Federativa do Brasil de 1988 , em seu artigo $216^{20}$, por exemplo, traçou os conceitos constitutivos do patrimônio cultural brasileiro, mencionando expressamente bens de natureza material e imaterial, individuais ou coletivos, carregados de referência à identidade e memória de diferentes grupos formadores da sociedade brasileira, incluindo formas de expressão, criação e vida; obras e espaços destinados às manifestações artístico-culturais; locais de valor histórico, paisagístico, artístico, arqueológico, paleontológico, ecológico e científico etc.

O universo da identidade cultural está intimamente ligado a ideais como civismo, ética e comprometimento nas relações sociais, às quais, somadas à liberdade de expressão, cidadania, garantia irrestrita de direitos humanos e sociais, formam um conjunto de valores que religa pessoas, grupos e intelectuais, pessoas que possuem em comum a defesa de uma (re)fundação antropológica capaz de alterar percepções, maneiras de pensar, valores e instaurar a cooperação em lugar da competição e a sabedoria no lugar do conhecimento lógico-racional. ${ }^{21}$

A questão cultural, pela sua extrema importância para a construção de uma identidade nacional, mostra-se, dessa forma, como um elemento que, mesmo em tempos de globalização, não pode ser descartado da análise sobre o processo de desenvolvimento. Assim, quando observamos um processo maciço de aculturação ${ }^{22}$ de determinados povos, mesmo embora, paralelamente, fenômenos de inculturação ${ }^{23}$ também se mostrem presentes em tempos globais,

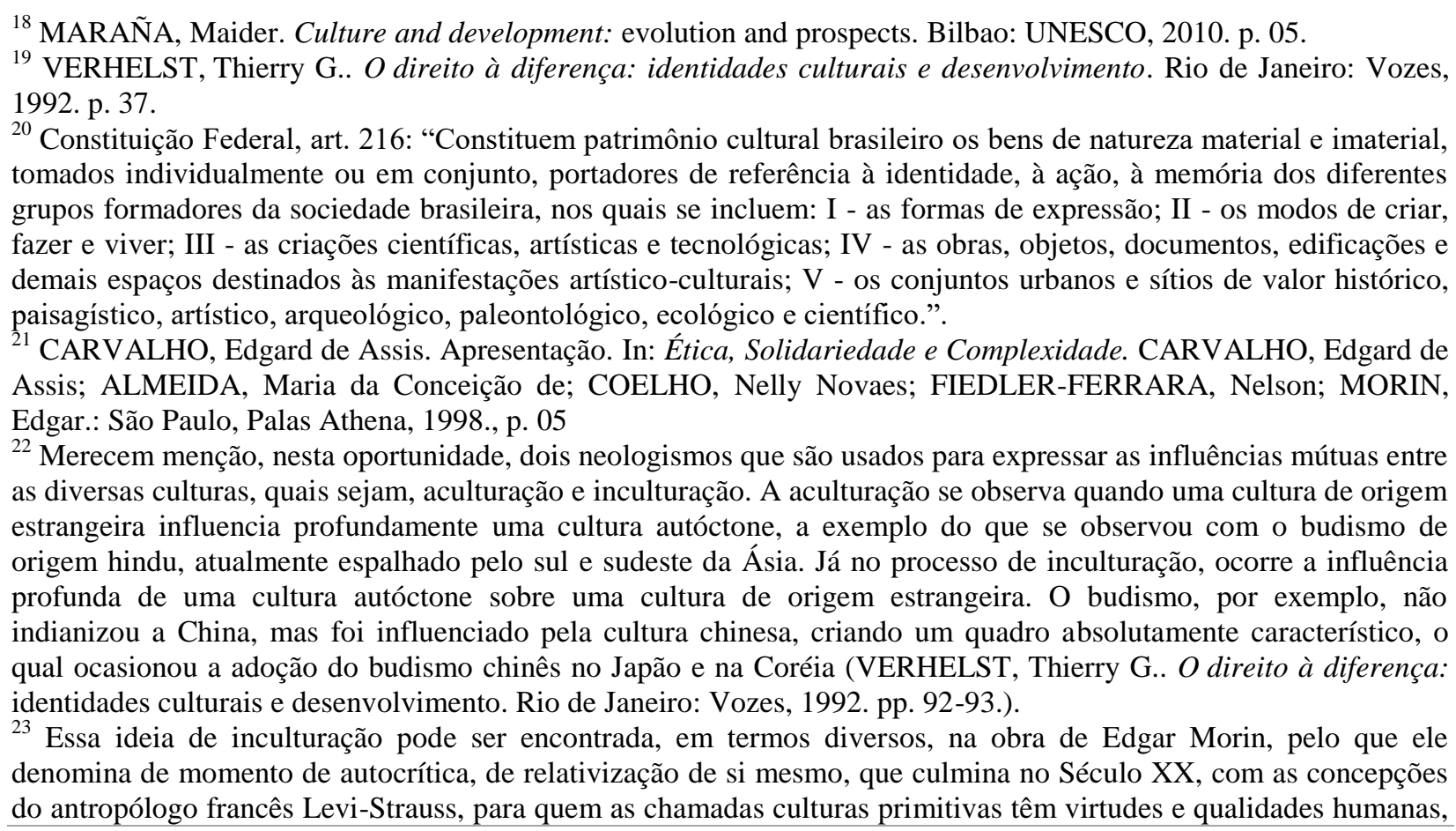
Revista de Direito Brasileira | São Paulo, SP | v. 19 | n. 8 | p. 3- 19 |Jan./Abr. 2018 
verifica-se o risco do imperialismo cultural, e os quadros de desapropriação cultural sacrificam o

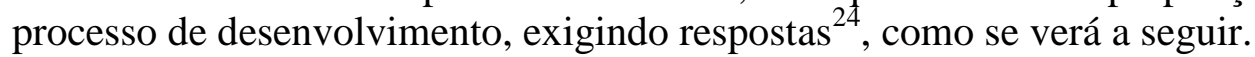

\section{O IMPACTO DA DESAPROPRIAÇÃO CULTURAL NO DIREITO AO DESENVOLVIMENTO}

O conceito de desenvolvimento, historicamente, mostrou-se atrelado ao poder políticomilitar, ao poder econômico ou, conforme observado especificamente ao longo do Século XX, ao crescimento econômico. O desafio que se apresenta para o novo século é exatamente transcender tais limitações teóricas, numa abordagem transdisciplinar, de amálgama, econômica, jurídica etc., observando o desenvolvimento como um todo ${ }^{25}$.

A abordagem ampla e inclusiva aponta para a constatação de que diferentes instituições interagem, quais sejam, mercado, legislatura, judiciário, imprensa, partidos políticos, empresas, organizações não-governamentais etc., e o sucesso dos esforços para o desenvolvimento de um país depende também dos resultados destas interações ${ }^{26}$.

Nesse prisma, a perspectiva jurídica se mostra parte relevante do processo de desenvolvimento, à medida que contribui para um quadro de estabilidade, garantindo o cumprimento de obrigações sociais e privadas, estimulando investimentos e criação de riqueza, o que afeta também as garantias de liberdade e de confiança na estrutura social ${ }^{27}$.

$\mathrm{O}$ direito ao desenvolvimento foi reconhecido por inúmeros instrumentos internacionais dos quais o Brasil é signatário, com ênfase para a Declaração sobre Direito ao Desenvolvimento (Resolução $n^{\circ}$ 41/128, da Assembléia Geral das Nações Unidas, 1986), que, em seu art. $1^{\circ}$, reconhece o desenvolvimento como um direito humano inalienável. Sobre a referida Declaração, Vladmir Oliveira da Silveira e Samyra Haydée Dal Farra Naspolini ${ }^{28}$ afirmam que

[...] foi a partir desse documento que o direito ao desenvolvimento se configurou como um direito humano inalienável e passou a ser entendido como um processo global econômico, social cultural e político, que tende ao melhoramento constante de toda a condição e qualidade de vida da população e dos indivíduos, sob a base de sua participação ativa, livre e significativa no processo de desenvolvimento e na distribuição dos benefícios de que dele derivam [...]. Ficou assim estabelecido que o principal responsável - ou seja, o sujeito passivo do direito ao desenvolvimento - é o Estado; isto é, é ele que tem

e a observação dessas comunidades revela que há conhecimentos ainda desconhecidos, como, por exemplo, sobre as qualidades de plantas e animais, dos quais estão mais próximas algumas populações indígenas da Amazônia (MORIN, Edgar. As duas globalizações: complexidade e comunicação, uma pedagogia do presente. Porto alegre: Sulina - Edipucrs, 2001. pp. 40-41.).

${ }^{24}$ VERHELST, Thierry G.. O direito à diferença: identidades culturais e desenvolvimento. Rio de Janeiro: Vozes, 1992. p. 93.

${ }^{25}$ BARRAL, Welber. Direito e desenvolvimento: um modelo de análise. In: Direito e Desenvolvimento: Análise da ordem jurídica brasileira sob a ótica do desenvolvimento. Welber Barral (Org.). São Paulo: Editora Singular, 2005. p. 32. SEN, Amartya. Reforma jurídica e reforma judicial no processo de desenvolvimento. Tradução Welber Barral. In: Direito e Desenvolvimento: Análise da ordem jurídica brasileira sob a ótica do desenvolvimento. Welber Barral (Org.). São Paulo: Editora Singular, 2005. p. 17.

${ }^{26}$ SEN, Amartya. Reforma jurídica e reforma judicial no processo de desenvolvimento. Tradução Welber Barral. In: Direito e Desenvolvimento: Análise da ordem jurídica brasileira sob a ótica do desenvolvimento. Welber Barral (Org.). São Paulo: Editora Singular, 2005. p. 27.

${ }^{27}$ BARRAL, Welber. Direito e desenvolvimento: um modelo de análise. In: Direito e Desenvolvimento: Análise da ordem jurídica brasileira sob a ótica do desenvolvimento. Welber Barral (Org.). São Paulo: Editora Singular, 2005. pp. 48-50.

${ }^{28}$ SILVEIRA, Vladmir Oliveira da e NASPOLINI, Samyra Haydée Dal Farra. Direito ao desenvolvimento no Brasil do Século XXI: uma análise da normatização internacional e da Constituição brasileira In: Direito e desenvolvimento no Brasil no Século XXI. Vladmir Oliveira da Silveira et al. (orgs.). Brasília: Ipea/CONPEDI, 2013. pp. 127-128.

Revista de Direito Brasileira | São Paulo, SP | v. 19 | n. 8 | p. 3- 19 |Jan./Abr. 2018 
o dever de criar as condições favoráveis ao desenvolvimento supranacional e interno dos povos e dos indivíduos.

No âmbito nacional, a Constituição brasileira faz referência ao desenvolvimento no seu preâmbulo e no seu artigo $3^{\circ}$, II, neste caso enquanto objetivo fundamental da República Federativa do Brasil. Nota-se, ainda, uma singela referência ao desenvolvimento tecnológico e econômico do País, especificamente ligada a inventos industriais, no artigo $5^{\circ}$, XXIX.

Entende-se, contudo, que, apesar da inexistência de menção expressa no texto constitucional, o direito ao desenvolvimento pode ser compreendido como direito fundamental, tanto pelo fundamento de que o conceito material de direito fundamental extrapola a previsão constitucional expressa, como pelo fato de que tal natureza está prevista em tratado internacional do qual o Brasil é parte, na esteira do artigo $5^{\circ}, \S 2^{\circ}$, da Constituição Federal.

Problemática atrelada à natureza de direito fundamental ao desenvolvimento é a questão da sua efetividade enquanto norma, ou seja, o resultado concreto da sua aplicação na sociedade, ligado, dessa forma, ao campo dos fatos ${ }^{29}$.

Dentro desse prisma da análise da efetividade do direito ao desenvolvimento, merece destaque o entendimento de Amartya Sen, que, criticando a economia descritiva, desligada da ética, por esta identificar as ideias de crescimento do Produto Nacional Bruto - PNB e desenvolvimento, afirma que precisam ser considerados como indicativos do desenvolvimento também outros fatores, como educação, saúde e os direitos civis ${ }^{30}$.

De acordo Com Gina Pompeu, uma vez que a ordem econômica e social brasileira está fundada no ideal de justiça social, calcada nos direitos de solidariedade, pode-se concluir que o constitucionalismo econômico dirigente possui o compromisso ético-social de promover o desenvolvimento nacional, observando tanto o âmbito econômico, quanto os valores sociais e humanos $^{31}$.

Nesse sentido, importante mencionar o último Rapport Mondial sur le Développement humain, divulgado pelo Programme des Nations Unies pour le Développement. O estudo analisou a situação de 188 (cento e oitenta e oito) países, utilizando como metodologia o IDH, índice que utiliza indicadores de renda, saúde e educação ${ }^{32}$.

No referido relatório, a Noruega permanece em $1^{\circ}$ lugar com o alto índice IDH 0,949; seguida por Austrália e Suíça, ambas com IDH 0,939. Na América do Sul, o Chile, ficou em $38^{\circ}$ lugar (IDH 0,847); a Argentina, em 45 lugar (IDH 0,827); o Uruguai, em 54 lugar (IDH 0,795); e a Venezuela, em $71^{\circ}$ lugar (IDH 0,767). A nota do Brasil (IDH 0,754) manteve-se estagnada, preservando-o em um patamar considerado alto pela $\mathrm{ONU}^{33}$.

\footnotetext{
${ }^{29}$ SARLET, Ingo Wolfgang. A eficácia dos direitos fundamentais: uma teoria geral dos direitos fundamentais na perspectiva constitucional. 10 ed. rev., atual. e ampl.. Porto Alegre: Livraria do Advogado, 2009. p. 240.

${ }^{30}$ SEN, Amartya. Desenvolvimento como liberdade. Tradução Laura Teixeira Motta. São Paulo: Companhia das Letras, 2000. p. 17.

${ }^{31}$ POMPEU, Gina vidal Marcílio e BERTOLINI, Adriana Rosas. A Ordem Econômica Internacional e Suas Implicações na Constituição Econômica Brasileira de 1988. Revista de Direito Brasileira. Florianópolis, Ano 3, Vol. 6, SET.-DEZ. / 2013, pp. 116-139. p. 132.

${ }^{32}$ NATIONS UNIES. Conseil économique et social. Rapport mondial sur le développement humain du Programme des Nations Unies pour le développement. E/CN.3/2001/18. ler déc. 2000. Français. Original: anglais. Disponível em: <https://unstats.un.org/unsd/statcom/doc01/2001-18f.pdf> Acesso em: 13 jun 2017

${ }^{33}$ NATIONS UNIES. Conseil économique et social. Rapport mondial sur le développement humain du Programme des Nations Unies pour le développement. E/CN.3/2001/18. 1er déc. 2000. Français. Original: anglais. Disponível em: <https://unstats.un.org/unsd/statcom/doc01/2001-18f.pdf> Acesso em: 13 jun 2017
} 
Contudo no indicador social, o número cai para IDH 0,561, o que denota que, se levado em consideração unicamente o fator social, o Brasil seria rebaixado para a escala de países com índice médio. 34

Nesse contexto, desenvolver seria introduzir em todas as partes da Terra os valores de organização e eficiência do mundo ocidental representado, sobretudo pela Europa e Estados Unidos. Ocorre que, mesmo diante da comprovada eficiência dos valores de organização adotados por esses países, os valores aplicados aos países desenvolvidos, por vezes, demonstramse inefetivos se implementados em países em desenvolvimento, tendo em vista a realidade social, econômica e cultural que é peculiar a cada nação.

De particular interesse neste ponto é a teoria da preservação da identidade cultural como elemento essencial ao desenvolvimento, de Thierry Verhelst, o qual descreve o desenvolvimento como sendo o Cavalo de Tróia do que chamou à época de "Terceiro Mundo", pois a este somente foi possível o crescimento mediante a violação de direitos, através da violência ou sedução, visto que, os mecanismos internos e externos de dominação econômica e política utilizavam-se de exploração e opressão, e são essas as suas causas estruturantes. ${ }^{35}$

Ao implementar valores europeus em nações em desenvolvimento, a possibilidade que ocorra um fenômeno denominado desapropriação cultural é evidente. Ainda que não se tenha estabelecido um conceito pacífico de "desapropriação cultural", a temática encontra-se em voga entre antropólogos e ativistas exigindo-se que, tão logo, o tema esteja no contexto jurídico.

Desta feita, sem a pretensão de exaurir a discussão ou incorrer em uma definição simplória sobre relevante tema, para a elaboração da definição de "desapropriação cultural" podese levar em conta que já existe definição jurídica para os conceitos constitutivos do patrimônio cultural brasileiro estando estabelecidos no artigo 216, da Constituição Federal, conforme citado anteriormente.

Se por patrimônio cultural entende-se bens de natureza material e imaterial, individuais ou coletivos, carregados de referência à identidade e memória de diferentes grupos formadores da sociedade brasileira, logo, desapropriação cultural é negar a determinado povo a utilização de elementos inerentes a sua identidade ou a menção à mesma, usurpando-lhes o autorreconhecimento, enquanto pertencente a determinado meio social, negando-lhes, por fim, o conhecimento de sua história.

Nesse contexto, Verhelst reflete sobre qual o preço a se pegar pelo desenvolvimento:

Até quando será que o Ocidente vai acreditar que está investido de uma missão caritativa em relação ao Terceiro Mundo? Primeiro, foi para "civilizá-lo" - e o Terceiro Mundo foi despojado de seus metais preciosos e de sua soberania; depois para desenvolvê-lo - e o Terceiro Mundo foi privado de suas matériasprimas; em seguida, foi para "modernizá-lo"; enquanto isso, o Norte se desfazia de seus excedentes industriais e, para cada dólar emprestado, obtinha de volta 3 dólares. Atualmente o Ocidente pretende "alimentá-lo". Desta vez, qual será o preço a pagar? $[\ldots]^{36}$

Um dos maiores preços a serem pagos pelo desenvolvimento é a desapropriação da identidade cultural, visto que, em todos os lugares do planeta, a integridade cultural e vitalidade dos diversos grupos humanos estão ameaçadas por estratégias de desenvolvimento que acentuam

\footnotetext{
${ }^{34}$ NATIONS UNIES. Conseil économique et social. Rapport mondial sur le développement humain du Programme des Nations Unies pour le développement. E/CN.3/2001/18. Ier déc. 2000. Français. Original: anglais. Disponível em: <https://unstats.un.org/unsd/statcom/doc01/2001-18f.pdf> Acesso em: 13 jun 2017

35 VERHELST, Thierry. O direito à diferença: identidades culturais e desenvolvimento. Rio de Janeiro: Vozes, 1992, p. 128

${ }^{36}$ VERHELST, Thierry G.. O direito à diferença: identidades culturais e desenvolvimento. Rio de Janeiro: Vozes, 1992. p 132.
}

Revista de Direito Brasileira | São Paulo, SP | v. 19 | n. 8 | p. 3- 19 |Jan./Abr. 2018 
o crescimento econômico ou a eficácia institucional a qualquer preço. Com frequência, os valores culturais dos países subdesenvolvidos são irremediavelmente deteriorados por modelos de mudança social fundamentados na globalização, consumo, competição, aquisição e manipulação das aspirações humana.

A comunidade internacional considera que é um dever velar pela manutenção preservação e defesa da identidade cultural de cada povo. Enfatiza que tudo isso demanda políticas culturais que protejam, estimulam e enriquecem a identidade e o patrimônio cultural, além de estabelecerem o mais absoluto respeito e apreço pelas minorias culturais e pelas outras culturas do mundo. A humanidade empobrece quando se ignora ou se destrói a cultura de um grupo determinado. ${ }^{37}$

\section{O PAPEL DAS ORGANIZAÇÕES NÃO-GOVERNAMENTAIS NA LUTA PELA MANUTENÇÃO DA CULTURA NACIONAL}

Diante do quadro de risco de desapropriação cultural, amplia-se a importância das Organizações Não-Governamentais na desmistificação das noções de desenvolvimento e de progresso, tendo em vista estarem muito mais próximas da realidade e das aspirações dos povos subdesenvolvidos do que muitas instâncias do poder. Sua finalidade deveria ser estabelecer formas exatas de resistência e de recuo cultural, visto que, as influências ocidentais são onipresentes, oferecendo simultaneamente coisas positivas e muitas coisas de caráter destrutivo ${ }^{38}$.

No que concerne à conjuntura nacional, algumas Organizações Não-Governamentais vêm cumprindo com o ideal de resistência e solidariedade, condenando o atraso gerado pelo etnocentrismo e propondo uma mudança de paradigma, defendendo que o desenvolvimento se dará principalmente por meio da recuperação e manutenção da identidade cultural individual e coletiva, promovendo desenvolvimento social através da educação e cultura.

Trata-se de iniciativa solidária de extrema relevância diante do quadro de complexidade do Brasil, por exemplo, se consideradas as suas dimensões continentais, a questão demográfica, sua diversidade regional e cultural etc.

Um bom exemplo disso é que, no ano de 2015, no ranking das cem Organizações NãoGovernamentais mais relevantes do mundo, quatro são brasileiras. O ranking global é liderado pela ONG Médicos Sem Fronteiras. Entre as organizações brasileiras, a Saúde Criança aparece na $21^{\mathrm{a}}$ posição; seguida pela Viva Rio, que aparece no $57^{\mathrm{a}}$ posição; Instituto da Criança, em $84^{\circ}$ lugar; e o Centro de Inclusão Digital, em $94^{\text {a }}$ posição ${ }^{39}$.

Para a confecção do guia das melhores Organizações Não-Governamentais do Brasil 2016, ainda sem previsão para divulgação do resultado, desde a abertura das inscrições, já foram mais de mil ONGs inscritas, de vinte e um Estados da Federação, cuja grande maioria possui programas de educação e promoção da cultura regional. ${ }^{40}$

$\mathrm{O}$ conceito de resistência e manutenção da integridade cultural são a marca de alguns projetos realizados por ONGs nacionais, tendo-se como exemplo o Olodum, ${ }^{41}$ que desenvolve

\footnotetext{
${ }^{37}$ BRASIL. Instituto do Patrimônio Histórico e Artístico Nacional. Conselho Nacional de Monumentos e Sítios. Conferência Mundial sobre as Políticas Culturais. Declaração do México. 1985, p. 02. Disponível em: <http://portal.iphan.gov.br/uploads/ckfinder/arquivos/Declaracao\%20do\%20Mexico\%201985.pdf>. Acesso em: 24 ago 2010

${ }^{38}$ VERHELST, Thierry G.. O direito à diferença: identidades culturais e desenvolvimento. Rio de Janeiro: Vozes, 1992. p 133-136.

${ }^{39}$ NGO ADVISOR. Top 500 NGOs: the international ranking of the world's top non-governmental organizations. 2015. Disponível em: < https://www.ngoadvisor.net/>. Acesso em: 13 jun 2017.

${ }^{40}$ NGO ADVISOR. Top 500 NGOs: the international ranking of the world's top non-governmental organizations. 2015. Disponível em: < https://www.ngoadvisor.net/>. Acesso em: 13 jun 2017.

${ }^{41}$ Olodum é um bloco afro do carnaval da cidade de Salvador, na Bahia. Fundado em 25 de abril de 1979 , é hoje uma organização não governamental do movimento negro brasileiro. Tem sua sede localizada no Centro Histórico de

Revista de Direito Brasileira | São Paulo, SP | v. 19 | n. 8 | p. 3- 19 |Jan./Abr. 2018
} 
projetos sociais em Salvador, implementando atividades culturais autóctones, como aulas de percussão. O mesmo ocorre com várias ONGs no Recife, que promovem aulas de Frevo. ${ }^{42}$ Ressalta-se que Recife não é apontada como exemplo por mero acaso. A capital pernambucana é atualmente pioneira na implantação de políticas públicas de incentivo à solidariedade, tornandose referência em voluntariado. ${ }^{43}$

Sendo oficialmente o maior país da América do Sul e quinto maior do mundo, o Brasil possui uma diversidade cultural condizente com suas proporções geográficas e heterogeneidade populacional. A riqueza da pluralidade cultural brasileira é evidente quando treze dos mil e trinta e um patrimônios culturais da humanidade encontram-se em solo brasileiro. $\mathrm{O}$ mais recente foi o conjunto da Pampulha, situado na capital belo-horizontina no estado de Minas Gerais. O estado possui ainda como Patrimônio Histórico Mundial da Humanidade, as cidades de Diamantina, Ouro Preto e Congonhas. Com quatro patrimônios históricos da humanidade, Minas Gerais tornase o estado com maior quantidade de honrarias culturais da federação. ${ }^{44}$

O primeiro estado que conteve seus bens tombados pela UNESCO foi o Distrito Federal, cujo contíguo urbanístico e arquitetônico é Patrimônio Mundial desde 1987. O estado de Goiás e seu conjunto arquitetônico, paisagístico e urbano do centro histórico de Goiás Velho, foi reconhecimento como Patrimônio Mundial em 2001. Olinda, no estado de Pernambuco, teve seu conjunto arquitetônico, urbanístico e paisagístico tombado pela Unesco em 1982. O estado do Maranhão, mais especificamente o centro histórico de São Luís, foi inscrito como Patrimônio Mundial em 1997. Já destacada pela incisa e eficaz atuação de suas ONGs, a cidade de Salvador, no estado Baiano, obteve tombamento de seus conjuntos monumentais da arquitetura religiosa, civil e militar em 1985.

A Primeira capital de Sergipe foi destruída pela invasão holandesa em 1630, e a arquitetura religiosa desenvolveu papel fundamental para a reconstrução da identidade cultural autóctone. São Cristóvão foi reconhecida como Patrimônio Mundial pela UNESCO em 2010. São Miguel das Missões, no estado do Rio Grande do Sul, possui um conjunto de cinco povoados identificados como território indígena Argentino e foi tombada em 1983. A capital do Estado do Rio de Janeiro foi reconhecida como Patrimônio Mundial incluindo monumentos como: o Pão de Açúcar, o Corcovado, a Floresta da Tijuca, o Aterro do Flamengo, o Jardim Botânico e a praia de Copacabana, totalizando cerca de aproximadamente duzentos e treze bens. E, por fim, a Serra da Capivara, no estado do Piauí, possui o Parque Nacional Serra da Capivara, com cerca de

Salvador, o Pelourinho, onde desenvolve ações de combate à discriminação social, estimula a autoestima e o orgulho dos afro-brasileiros, agrega expressões de vida e tradições, cultivando um senso de continuidade dos valores socioculturais africanos, defende e luta para assegurar os direitos civis e humanos das pessoas marginalizadas, na Bahia e no Brasil. A Escola Olodum tornou-se um espaço real de participação e expressão da comunidade negra, é uma ONG de referência nacional e internacional pela inovação no trabalho com arte, educação e pluralidade cultural. OLODUM. Olodum Social. Disponível em: < http://olodum.com.br/olodum-social/>. Acesso em: 05 jun 2017.

${ }^{42}$ Trata-se de uma forma de expressão musical, coreográfica e poética, enraizada no Recife e em Olinda, no estado de Pernambuco. Refere-se a um gênero musical urbano que surgiu no final do século 19, no carnaval, em um momento de transição e efervescência social como uma forma de expressão popular nessas cidades. $\mathrm{O}$ frevo foi reconhecido como Patrimônio Imaterial da Humanidade, título que abrange práticas e expressões vivas passadas de uma geração à outra. Inclui tradições orais, artes performáticas, práticas sociais, eventos celebrativos, sabedorias e práticas relacionadas à natureza e ao universo, assim como os saberes e habilidades de trabalhos artesanais tradicionais da região pernambucana. UNESCO. United Nations Educational, Scientific and Cultural Organization. Intangible cultural heritage: a force for sustainable development. 23 out 2013. Disponível em: < http://www.unesco.org/new/en/media-services/in-focus-articles/intangible-cultural-heritage-for-sustainable-

development/>. Acesso em: 13 jun 2017

${ }^{43}$ NEIVA. Ana Paula. Coordenador da ONG Novo Jeito mostra porque Recife é referência em voluntariado. Diário de Pernambuco. 31 ago 2015. Disponível em:< http://www.diariodepernambuco.com.br/app/noticia/vidaurbana/2015/08/31/interna_vidaurbana,595352/coordenador-da-ong-novo-jeito-mostra-porque-recife-e-referenciaem-voluntariado.shtml>. Acesso em: 05 jun 2017

${ }^{44}$ BRASIL. Instituto Estadual do Patrimônio Histórico e Artístico - IEPHA-MG. Tombamentos e Registros. Disponível em< http://www.iepha.mg.gov.br/index.php/servicos/tombamento-e-registro>. Acesso em: 24 ago 2017.

Revista de Direito Brasileira | São Paulo, SP | v. 19 | n. 8 | p. 3- 19 |Jan./Abr. 2018 
quatrocentos sítios arqueológicos, que preservam vestígios da mais remota presença do homem na América do Sul, é considerada centro de referência de estudos arqueológicos e foi tombada em 1991. ${ }^{45}$

No que concerne ao Patrimônio Nacional, Canclini examina que:

Se é verdade que o patrimônio serve para unificar uma nação, as desigualdades na sua formação e apropriação exigem que se o estude, também, como espaço de luta material e simbólica entre as classes, as etnias e os grupos. Este princípio metodológico corresponde ao caráter complexo das sociedades contemporâneas. ${ }^{46}$

Reconhecer a necessidade da preservação da identidade não significa, contudo, rejeitar a modernidade ou de retornar ao passado. Trata-se de tomar consciência dos fracassos e avaliar suas causas. A cada povo cabe, assim, reconstruir suas sociedades, conciliando passado e presente, numa modernidade sui generis ${ }^{47}$.

Manter a integridade cultural dos países em desenvolvimento é garantir que determinada nação tenha condições de manter-se socialmente unida em virtude dos laços de identidade entre eles estabelecidos. Em termos diversos, é garantir às gerações futuras, mesmo inseridas em uma sociedade globalizada, a possibilidade de conhecer seu passado e construir conjuntamente um futuro diverso do que lhe foi destinado, numa iniciativa de solidariedade ${ }^{48}$.

\section{O CAMINHO DA SOLIDARIEDADE}

O direito ao desenvolvimento está incluído dentre os direitos fundamentais de terceira dimensão $^{49}$, também denominados de direitos de solidariedade. Tratam-se de direitos de titularidade coletiva ou difusa, indefinida e indeterminável, que se desprendem da noção de indivíduo como titular e são resultantes de reivindicações geradas pelo impacto tecnológico, pelo estado crônico de beligerância, pelo processo de descolonização do segundo pós-guerra etc. Dentro deste quadro, torna-se necessário um esforço em escala mundial para sua efetivação, ou seja, uma responsabilidade transnacional, calcada na solidariedade ${ }^{50}$.

${ }^{45}$ BRASIL. Portal Brasil. Cultura. Bens Tombados. Brasil tem 13 locais considerados Patrimônio Cultural da Humanidade. Disponível em: < http://www.brasil.gov.br/turismo/2016/07/brasil-tem-13-locais-consideradospatrimonio-cultural-da-humanidade>. Acesso em: 24 ago 2017

${ }^{46}$ CANCLINI, Nestor Garcia. O patrimônio cultural e a construção imaginária do nacional. Revista do Patrimônio Histórico e Artístico Nacional, Rio de Janeiro, n. 23, p. 95-115, 1994.

${ }^{47}$ VERHELST, Thierry G.. O direito à diferença: identidades culturais e desenvolvimento. Rio de Janeiro: Vozes, 1992. p. 104.

48 VERHELST, Thierry G.. O direito à diferença: identidades culturais e desenvolvimento. Rio de Janeiro: Vozes, 1992. p 134.

49 A opção terminológica pelo termo "dimensões" dos direitos fundamentais leva em consideração a doutrina de Ingo Sarlet, para quem não há como se negar "que o reconhecimento progressivo de novos direitos fundamentais tem o caráter de um processo cumulativo, de complementaridade, e não de alternância, de tal sorte que o uso da expressão 'gerações' pode ensejar a falsa impressão da substituição gradativa de uma geração por outra" (SARLET, Ingo Wolfgang. A eficácia dos direitos fundamentais: uma teoria geral dos direitos fundamentais na perspectiva constitucional. 10 ed. rev., atual. e ampl.. Porto Alegre: Livraria do Advogado, 2009. p. 45).

${ }^{50}$ SARLET, Ingo Wolfgang. A eficácia dos direitos fundamentais: uma teoria geral dos direitos fundamentais na perspectiva constitucional. 10 ed. rev., atual. e ampl.. Porto Alegre: Livraria do Advogado, 2009. pp. 48-49. FEITOSA, Maria Luiza Alencar Mayer. Exclusão social e pobreza nas interfaces entre o direito econômico do desenvolvimento e o direito humano ao desenvolvimento. In: Direito e desenvolvimento no Brasil no Século XXI. Vladmir Oliveira da Silveira et al. (orgs.). Brasília: Ipea/CONPEDI, 2013. p. 115.

Revista de Direito Brasileira | São Paulo, SP | v. 19 | n. 8 | p. 3- 19 |Jan./Abr. 2018 
Discorrer sobre direito ao desenvolvimento significa, assim, reafirmar os ideais de solidariedade, superação da miséria, melhoria das condições socioeconômicas e realização integral da pessoa humana com dignidade ${ }^{51}$.

Referência no tema da solidariedade, Edgar Morin ${ }^{52}$ ensina que:

[...] em nosso mundo de homens, no qual as forças de separação, recolhimento, ruptura, deslocamento, ódio, são cada vez mais poderosas, mais do que sonhar com a harmonia geral ou com o paraíso, devemos reconhecer a necessidade vital, social e ética de amizade, de afeição e de amor pelos seres humanos, os quais, sem isso, viveriam de hostilidade e de agressividade, tornando-se amargos ou perecendo.

ainda:

Na aclamada obra "A Via para o futuro da humanidade", o referido autor ${ }^{53}$ destaca,

A solidariedade anônima do Estado-Providência, ${ }^{54}$ com seus dispositivos de segurança e assistências de todas as ordens, é insuficiente. Há necessidade de uma solidariedade concreta e vivenciada, de pessoa para pessoa, de grupos para pessoas, de pessoa para grupos. [...] Não se trata, contudo, de promulgar a solidariedade, mas de liberar a força não empregada das boas vontades e de favorecer as ações de solidariedade. Segundo nossa concepção do indivíduosujeito, todo sujeito humano traz consigo dois quase-softwares: um é o da autoafirmação egocêntrica que o Ego-Eu expressa, vital para se alimentar, se defender, se desenvolver; o outro é os software do Nós, que inscreve o Eu em uma relação de amor ou de comunidade no seio de sua família, de sua pátria, de seu pertencimento religioso, de seu partido. Nossa civilização superdesenvolveu o primeiro software e subdesenvolveu o segundo. Mas este encontra-se apenas adormecido; trata-se de incitá-lo a despertar.

Ao relacionar solidariedade e justiça, Habermas ${ }^{55}$ afirma que:

A justiça concebida deontologicamente exige, como sua outra face, a solidariedade. Não se trata, neste caso, de dois momentos que se complementam, mas de aspectos da mesma coisa. Toda moral autônoma tem que resolver, ao mesmo tempo, duas tarefas: ao reivindicar trato igual, e com ele um respeito equivalente pela dignidade de cada um, faz valer a inviolabilidade dos indivíduos na sociedade; e ao mesmo tempo em que exige a solidariedade por parte dos indivíduos, como membros de uma comunidade na qual são socializados, protege as relações intersubjetivas de reconhecimento recíproco. A justiça refere-se à igualdade da liberdade dos indivíduos que se determinam a si mesmos e que são insubstituíveis, enquanto a solidariedade refere-se ao bem, ou à felicidade dos companheiros irmanados em uma forma de vida intersubjetivamente compartilhada, e deste modo também à preservação da integridade dessa forma de vida. As normas não podem proteger um sem o

${ }^{51}$ WOLKMER, Antonio Carlos e WOLKMER, Maria de Fátima. Direitos humanos e desenvolvimento. In: Direto $e$ Desenvolvimento: Análise da ordem jurídica brasileira sob a ótica do desenvolvimento. Welber Barral (Org.). São Paulo: Editora Singular, 2005. p. 62.

${ }^{52}$ MORIN, Edgar. O Método VI: ética. 2. ed. Tradução de Juremir Machado da Silva. Porto Alegre: Porto Alegre: Sulina, 2005. p. 36.

${ }^{53}$ MORIN, Edgar. A via para o futuro da humanidade. Tradução de Edgard de Assis Carvalho e Mariza perassi Bosco. Rio de Janeiro: Bertrand Brasil, 2013. pp. 76-77.

${ }^{54}$ Conceito da ciência política para o qual o Estado é mentor e organizador das atividades econômicas em geral. Embora originário da Europa, o papel do Estado-Providência se reafirmou na economia globalizada. (N.Ts)

${ }^{55}$ HABERMAS, Jürgen. Aclaraciones a la ética del discurso. Madrid: Trotta, 2000. pp. 75-76. 
outro, isto é, não podem proteger a igualdade de direitos e as liberdades dos indivíduos sem o bem do próximo e da comunidade a que eles pertencem.

O princípio da solidariedade foi introduzido no ordenamento jurídico brasileiro por intermédio do art. 3º, I, da Constituição Federal de 1988, como pressuposto do Estado Democrático de Direito, volvido para a convivência em um ambiente social focado em construir uma sociedade livre, justa e solidária, ideais, que, se devidamente utilizados, auxiliam na concretização da promessa de justiça social e no desenvolvimento nacional ${ }^{56}$.

A solidariedade, considerada como marca do Estado Democrático de Direito, implica concluir que Estado e indivíduo assumem uma aliança, visando incrementar direitos básicos destes, promoção de políticas de erradicação da pobreza e de redução das desigualdades ${ }^{57}$.

Uma vez incluída como objetivo fundamental, pela Constituição Federal, o entendimento sobre a solidariedade deve ser o de que a República Federativa do Brasil deve construir uma ordem de homens livres, com responsabilidade e apoio recíprocos, em que a justiça distributiva e retributiva prevaleça como fator de dignificação, voltando-se para a realização do bem-estar social ${ }^{58}$.

Isso significa que, para além da atuação do Estado, cada pessoa deve atuar em relação à outra com cooperação, assistência, amparo, ajuda e cuidado, num vínculo de sentimento racionalmente guiado, com consciência de interdependência social ${ }^{59}$.

A solidariedade realiza-se, então, como um ato complexo, no qual concorrem o Poder Público e a própria sociedade, apontando a Constituição Federal as diretrizes ideológicas, políticas e jurídicas para sua otimização e implementação, ao acolher os princípios da dignidade humana e do pluralismo social e político ${ }^{60}$.

O caminho da solidariedade, dentro de um quadro democrático, implica, assim, admitir direitos e deveres nas relações interindividuais, como cooperação e respeito, exigindo esta postura não só do Estado, mas também de cada cidadão em relação a todos os demais, e de cada Estado em relação aos demais, no que tange à esfera transnacional, o que também significa respeitar e colaborar para a manutenção das culturas locais.

Essa visão da contribuição da solidariedade para a manutenção e respeito das culturas locais, de suma importância para o tema do desenvolvimento, bem como o reconhecimento de que as diversidades culturais influenciam a própria ideia de solidariedade, para além da cultura judaico-cristã, podem lastrear quiçá a utilização das expressões solidariedade intercultural e solidariedade sociocultural $^{61}$.

\section{CONCLUSÃO}

A sociedade contemporânea tem exigido dos operadores do Direito à busca de alternativas para os efeitos negativos da revolução industrial, da globalização e do ideal de crescimento que tem como foco exclusivamente o viés econômico, diante da imprevisibilidade e da complexidade do sistema social, demonstrando a necessidade de se recorrer à transdisciplinaridade para solucionar tal quadro.

\footnotetext{
${ }^{56}$ SILVA, José Afonso da. Curso de Direito Constitucional Positivo. 23 ed. São Paulo: Malheiros, 2004. p. 765..

${ }^{57}$ CARDOSO, Alenilton da Silva. Princípio da solidariedade: o paradigma ético do direito contemporâneo. São Paulo: Juarez de Oliveira, 2010. pp. 109, 116, 122 e 151.

${ }^{58}$ SILVA, José Afonso da. Comentário contextual à Constituição. 6. ed. atual.. São Paulo: Malheiros, 2009. pp. 4647

${ }^{59}$ LÔBO, Paulo Luiz Netto. Direito civil: parte geral. São Paulo: Saraiva, 2009. p. 81.

${ }^{60}$ DINIZ, Márcio Augusto de Vasconcelos. Estado social e o princípio da solidariedade. Nomos: Revista do Curso de Mestrado em direito da UFC. Fortaleza, v. 26, pp. 171-185, janeiro-junho de 2007. p. 173.

${ }^{61}$ VERHELST, Thierry G.. O direito à diferença: identidades culturais e desenvolvimento. Rio de Janeiro: Vozes, 1992. p 134.
} 
A concretização do direito ao desenvolvimento, além de respeitar o viés econômico, deve atentar para critérios de ordem social, ambiental e cultural, evitando-se a desapropriação cultural nos países em desenvolvimento, fenômeno deletério que tem sido observado através da difusão generalizada dos valores e costumes do mundo ocidental como um padrão para todo o planeta.

Neste movimento de se evitar a desapropriação cultural, para que o desenvolvimento se estabeleça conforme as demandas identitárias e peculiares de cada povo, o trabalho das organizações não governamentais tem sido crucial, haja vista a proximidade que estas constroem com a base social, permitindo um melhor mapeamento das necessidades e demandas locais.

Conclui-se que a ligação entre a preservação da identidade cultural e o desenvolvimento dos povos se concretiza através da solidariedade, que promove uma mudança de paradigma, estimulando o sentimento de coalizão que transformava os países subdesenvolvidos em verdadeiras nações, permitindo, para as gerações futuras, a união entre a preservação do passado e a construção do futuro e resgatando o desenvolvimento no mais intrínseco aspecto, qual seja, o desenvolvimento humano, o que deve ser fortemente estimulado.

\section{REFERÊNCIAS BIBLIOGRÁFICAS}

BARRAL, Welber. Direito e desenvolvimento: um modelo de análise. In: Direito e Desenvolvimento: Análise da ordem jurídica brasileira sob a ótica do desenvolvimento. Welber Barral (Org.). São Paulo: Editora Singular, 2005.

BAUMAN, Zygmunt. Globalização: as consequências humanas. Tradução Marcus Penchel. Rio de Janeiro: Zahar, 1999.

BRASIL. Constituição da República Federativa do Brasil. Brasília, 5 out 1988.

BRASIL. Instituto Estadual do Patrimônio Histórico e Artístico - IEPHA-MG. Tombamentos e Registros. Disponível em< http://www.iepha.mg.gov.br/index.php/servicos/tombamento-eregistro>. Acesso em: 24 ago 2017.

BRASIL. Instituto do Patrimônio Histórico e Artístico Nacional. Conselho Nacional de Monumentos e Sítios. Conferência Mundial sobre as Políticas Culturais. Declaração do México. 1985, p. $02 . \quad$ Disponível em: <http://portal.iphan.gov.br/uploads/ckfinder/arquivos/Declaracao\%20do\%20Mexico\%201985.pd f>. Acesso em: 24 ago 2010

CARVALHO, Edgard de Assis. Apresentação. In: Ética, Solidariedade e Complexidade. CARVALHO, Edgard de Assis; ALMEIDA, Maria da Conceição de;

COELHO, Nelly Novaes; FIEDLER-FERRARA, Nelson; MORIN, Edgar. São Paulo, Palas Athena, 1998.

CANCLINI, Nestor Garcia. O patrimônio cultural e a construção imaginária do nacional. Revista do Patrimônio Histórico e Artístico Nacional, Rio de Janeiro, n. 23, p. 95-115, 1994.

CARDOSO, Alenilton da Silva. Princípio da solidariedade: o paradigma ético do direito contemporâneo. São Paulo: Juarez de Oliveira, 2010.

DELGADO, Ana Paula Teixeira. O direito ao desenvolvimento na perspectiva da globalização: paradoxos e desafios. Rio de Janeiro: Renovar, 2001. 
DINIZ, Márcio Augusto de Vasconcelos. Estado social e o princípio da solidariedade. Nomos: Revista do Curso de Mestrado em direito da UFC. Fortaleza, v. 26, pp. 171-185, janeiro-junho de 2007.

DREIFUSS, René Armand. A época das perplexidades: mundialização, globalização e planetarização: novos desafios. Petrópolis: Vozes, 1997.

FEITOSA, Maria Luiza Alencar Mayer. Exclusão social e pobreza nas interfaces entre o direito econômico do desenvolvimento e o direito humano ao desenvolvimento. In: Direito e desenvolvimento no Brasil no Século XXI. Vladmir Oliveira da Silveira et al. (orgs.). - Brasília: Ipea/CONPEDI, 2013.

FERREIRA, Aurélio Buarque de Holanda. Novo dicionário Aurélio da língua portuguesa. 3 ed. Curitiba: Positivo, 2004.

FURTADO, Celso. O mito do desenvolvimento econômico. 4 ed. Rio de Janeiro: Paz e Terra, 1974.

GIDDENS, Anthony. Mundo em descontrole. Trad. Maria Luiza X. de A. Borges. 2 ed.. Rio de Janeiro: Record, 2002.

POMPEU, Gina vidal Marcílio e BERTOLINI, Adriana Rosas. A Ordem Econômica Internacional e Suas Implicações na Constituição Econômica Brasileira de 1988. Revista de Direito Brasileira. Florianópolis, Ano 3, Vol. 6, SET.-DEZ. / 2013, pp. 116-139.

HABERMAS, Jürgen. Aclaraciones a la ética del discurso. Madrid: Trotta, 2000.

LÔBO, Paulo Luiz Netto. Direito civil: parte geral. São Paulo: Saraiva, 2009.

MORIN, Edgar. A via para o futuro da humanidade. Tradução Edgard de Assis Carvalho e Mariza Perassi Bosco. Rio de Janeiro: Bertrand Brasil, 2013.

MORIN, Edgar. As duas globalizações: complexidade e comunicação, uma pedagogia do presente. Porto alegre: Sulina - Edipucrs, 2001.

MORIN, Edgar. O Método VI: ética. 2. ed. Tradução de Juremir Machado da Silva. Porto Alegre: Porto Alegre: Sulina, 2005.

NEIVA. Ana Paula. Coordenador da ONG Novo Jeito mostra porque Recife é referência em voluntariado. Diário de Pernambuco. 31 ago 2015.

NGO ADVISOR. Top 500 NGOs: the international ranking of the world's top non-governmental organizations. 2015.

SANTOS, Milton. Por uma outra globalização: do pensamento único à consciência universal. 6 ed.. Rio de Janeiro: Record, 2001. 
SARLET, Ingo Wolfgang. A eficácia dos direitos fundamentais: uma teoria geral dos direitos fundamentais na perspectiva constitucional. 10 ed. rev., atual. e ampl.. Porto Alegre: Livraria do Advogado, 2009.

SEN, Amartya. Desenvolvimento como liberdade. Tradução Laura Teixeira Motta. São Paulo: Companhia das Letras, 2000.

SEN, Amartya. Reforma jurídica e reforma judicial no processo de desenvolvimento. Tradução Welber Barral. In: Direito e Desenvolvimento: Análise da ordem jurídica brasileira sob a ótica do desenvolvimento. Welber Barral (Org.). São Paulo: Editora Singular, 2005.

SILVA, José Afonso da. Comentário contextual à Constituição. 6. ed. atual.. São Paulo: Malheiros, 2009.

SILVA, José Afonso da. Curso de Direito Constitucional Positivo. 23 ed. São Paulo: Malheiros, 2004.

SILVEIRA, Vladmir Oliveira da; NASPOLINI, Samyra Haydée Dal Farra. Direito ao desenvolvimento no Brasil do Século XXI: uma análise da normatização internacional e da Constituição brasileira In: Direito e desenvolvimento no Brasil no Século XXI. Vladmir Oliveira da Silveira et al. (orgs.). Brasília: Ipea/CONPEDI, 2013. pp. 127-128.

STIGLITZ, Joseph E. A Globalização e seus malefícios: a promessa não cumprida de benefícios globais. São Paulo: Futura, 2002.

UNESCO. United Nations Educational, Scientific and Cultural Organization. Intangible cultural heritage: a force for sustainable development. 23 out 2013.

VERHELST, Thierry G.. O direito à diferença: identidades culturais e desenvolvimento. Rio de Janeiro: Vozes, 1992.

WOLKMER, Antônio Carlos e WOLKMER, Maria de Fátima. Direitos humanos e desenvolvimento. In: Direito e Desenvolvimento: Análise da ordem jurídica brasileira sob a ótica do desenvolvimento. Welber Barral (Org.). São Paulo: Editora Singular, 2005. 